\title{
Loss of CB1 receptors leads to differential age-related changes in reward-driven learning and memory
}

\section{Onder Albayram *, Andras Bilkei-Gorzo and Andreas Zimmer}

Institute of Molecular Psychiatry, University of Bonn, Bonn, Germany

\section{Edited by:}

Gizem Donmez, Tufts University

School of Medicine, USA

\section{Reviewed by:}

Junming Wang, University of

Mississippi Medical Center, USA

Ashok Kumar, University of Florida,

USA

${ }^{*}$ Correspondence:

Onder Albayram, Institute of

Molecular Psychiatry, University of

Bonn, Sigmund-Freud-Str. 25,

53127 Bonn, Germany.

e-mail:oalbayram@gmail.com
Previous studies have shown that cannabinoid 1 (CB1) receptor signaling dissociates between reward-associated and aversive memories. The influence of CB1 receptors on the aversion-driven spatial learning in the Morris water maze test is strongly age-dependent: mice with genetic deletion of CB1 receptors $\left(\mathrm{Cnr}^{-/-}\right)$show superior learning when young but inferior learning when old compared to age-matched wild-type mice. Whether the reward-driven spatial learning is influenced in the same way by CB1 receptor signaling as the aversion-driven learning remains unclear. Thus, we examined the performance of $\mathrm{Cn}^{-/-}$and their wild-type littermates at ages of 2-, 5-, and 12-months-old in the eight-arm radial maze test-a reward-motivated model of spatial learning. Interestingly, 2-months-old $\mathrm{Cnr}^{-/-}$mice had a superior learning ability to wild-type mice. At the age of 5-months, $\mathrm{Cnr}^{-1-}$ mice showed the same performance as the wild-type littermates. However, 12-months-old $\mathrm{Cnr}^{-/-}$mice showed significantly impaired performances in each parameter of the test. Accordingly, this study provides compelling support for our previous result that genetic deletion of CB1 receptor leads to early onset of age-related memory decline, similarly affecting both reward and aversion-driven learning.

Keywords: cannabinoid receptor, aging, emotional valence, motivation, spatial learning, mice

\section{INTRODUCTION}

Emotional arousal facilitates memory formation therefore memories about highly emotional situations are usually vivid, longlasting, and resistant to extinction. The cannabinoid system influences the formation, extinction and reconsolidation of emotional memories but the latter two phases are dependent on the emotional significance of the memory. Increased endocannabinoid signaling either via inhibition of endocannabinoid uptake (Chhatwal and Ressler, 2007) or inhibition of anandamide degradation (Varvel et al., 2007) facilitates the extinction of fearrelated memories whereas pharmacological or genetic blockade of cannabinoid 1 (CB1) receptors impairs fear memory extinction (Marsicano et al., 2002). The extinction of reward-related memories is not affected by pharmacological activation or blockade (Manwell et al., 2009) or by genetic deletion of CB1 receptors (Holter et al., 2005). The effect of cannabinoids on the reinstatement of fear- and reward-associated memories also differs. Activation of $\mathrm{CB} 1$ receptors blocks the reconsolidation of fear memories (Chhatwal and Ressler, 2007), whereas the reinstatement of reward-associated memories are decreased by CB1 antagonists (Ward et al., 2009). The dissociation between the effects of the cannabinoid system on fear and reward-associated memory was also shown in humans. Carriers of a minor gene variant of the fatty acid amide hydrolase, the degrading enzyme of the endogenous cannabinoid anandamide, show decreased threat-related reactivity in the amygdala but elevated reactivity to reward related signals in the ventral striatum compared to bearers of the major allele (Hariri et al., 2009). We have previously shown that the effect of $\mathrm{CB} 1$ receptor on spatial memory depends on the age of the animal: animals lacking $\mathrm{CB} 1$ receptors $\left(\mathrm{Cnrl}^{-/-}\right)$at the age of 6-weeks showed an improved performance in the Morris water maze test whereas 12-monthsold $\mathrm{Cnr}^{-/-}$mice showed inferior performance (Albayram et al., 2011). The Morris water maze is one of the most widely used behavioral model to test hippocampus-dependent spatial learning and memory (Morris et al., 1982). This model is aversiondriven because being in water is aversive for mice and they try to escape to dryer territory (Akirav et al., 2001). Whether the effect of CB1 receptor on reward-motivated learning is also age-dependent is not known. Therefore we now asked whether the learning phenotype of $\mathrm{Cnr}^{-/-}$mice in the rewarddriven eight-arm radial maze model also differs between the age groups.

\section{MATERIALS AND METHODS ANIMALS}

Experiments to test the consequence of a constitutive deletion of the CB1 receptor were carried out with group-housed male and female $\mathrm{Cnrl}^{-/-}$and $\mathrm{Cnrl}^{+/+}$littermates on a congenic C57BL6/J background at 2, 5, and 12 months of age (Zimmer et al., 1999). Care of the animals and conduction of all experiments followed the guidelines of European Communities Directive 86/609/EEC and the 1998 German Animal Protection Law regulating animal research. 


\section{EIGHT-ARM RADIAL MAZE}

The procedure was carried out with slight modifications as described previously (Heldt et al., 2007). Briefly, the eight-arm radial maze was constructed of white painted wood. It consisted a central platform $(30 \mathrm{~cm}$ in diameter) with eight-arms $(70 \times 10 \mathrm{~cm})$ surrounded by walls $(10 \mathrm{~cm}$ in height $)$ and placed in a sound and light isolated room with a camera on the ceiling. The behavior of the animals was followed by an experienced observer unaware of the genotype from an adjacent room through a monitor and evaluated using The Observer software (Noldus, Netherland). During the training, animals were single housed and maintained at $80-90 \%$ of their body weight by dietary restriction. To familiarize the animals to the radial maze, the mice received one daily habituation session for 4 days prior to training. During the habituation trial, all the eight-arms are baited with 1 food pellet, and the mouse was allowed to explore freely until it had taken all the pellets. After habituation, all mice were tested with 1 trial per day for 17 days (Figure 1). During the test trial, four randomly selected arms are baited with 1 pellet of food each; the baited arms are kept unchanged throughout the experiment. The mouse is allowed to move freely in the maze until it has collected the 4 pellets of food or until $10 \mathrm{~min}$ have elapsed, whichever occurs first. Entry into a non-baited arm was scored as a reference memory error, while re-entry into baited arms that had been previously visited was scored as a working memory error. The decrease in the number of arm entries per trial was used to indicate memory acquisition. The effect of deletion of $\mathrm{CB} 1$ receptor on the performance was evaluated separately in the age groups using Three-Way mixed ANOVA (between factors: genotype, sex; within factor: trial) followed by Bonferroni test.

\section{RESULTS}

The total number of arm entries required to collected the food pellets or reach the cut-off time was significantly lower in 2-months-old $\mathrm{Cnr1}^{-/}$(genotype effect: $F_{(1,264)}=8.28$, $p<0.01$ ) (Figure 2A1) and higher in 12-months-old Cnr1-/- (genotype effect: $\left.F_{(1,264)}=13.93, p<0.001\right) \quad($ Figure 2C1) mice compared to age-matched WT controls. However, the number of arm entries did not differ between the genotypes at 5 months of age (genotype effect: $F_{(1,264)}=2.63$, N.S.) (Figure 2B1). The sex of the animals did not influence the mean number of arm entries (Genotype $\times$ sex effect: 2 -months-old: $F_{(1,11)}=0.811$; N.S.; 5 -months-old: $\quad F_{(1,11)}=0.731 ; \quad$ N.S.; 12-months-old: $\quad F_{(1,11)}=0.805$; N.S.) (Figures 2A2,B2,C2, respectively).

The number of working (Figure 3) - and reference (Figure 4)-memory errors generally showed similar results as the total number of arm entries. 2-months-old $\mathrm{Cnrl}^{-/-}$ animals showed significantly less errors (the number of working memory errors: genotype effect: $F_{(1,264)}=8.30, p<0.01$; the number of reference memory errors: genotype effect: $\left.F_{(1,264)}=8.55, \quad p<0.01\right) \quad$ while 12 -months-old $\mathrm{Cnr1}^{-/-}$ animals made more errors (the number of working memory errors: genotype effect: $F_{(1,264)}=14.39, p<0.001$; the number of reference memory errors: genotype effect: $F_{(1,264)}=8.88$, $p<0.01)$ during the task compared to age-matched WT littermates. There was no difference in both parameters at 5 months of age between $\mathrm{Cnrl}^{-/-}$and $\mathrm{Cnr}^{+/+}$mice (the number of working memory errors: genotype effect: $F_{(1,264)}=2.41$, N.S.; the number of reference memory errors: genotype effect: $F_{(1,264)}=2.11$, N.S.). The sex of the animals also did not influence the number of working memory errors (Genotype $\times$ sex effect: 2-months-old: $F_{(1,11)}=0.829$; N.S.; 5-months-old: $F_{(1,11)}=0.778$; N.S.; 12-months-old: $F_{(1,11)}=0.833$; N.S.) or the number of reference errors (Genotype $\times$ sex effect: 2 -monthsold: $F_{(1,11)}=1.209$; N.S.; 5-months-old: $F_{(1,11)}=0.678$; N.S.; 12-months-old: $F_{(1,11)}=0.245$; N.S.).

It was previously suggested that high levels of vigorous and impulsive activity, which is typical in young rodents, could interfere with the performance in learning paradigms (Dodart et al., 1999; Ward et al., 1999). This phenomenon was also present in our study: in the first phase of the experiment at days 1-3, the speed of the young animals expressed as number of arm

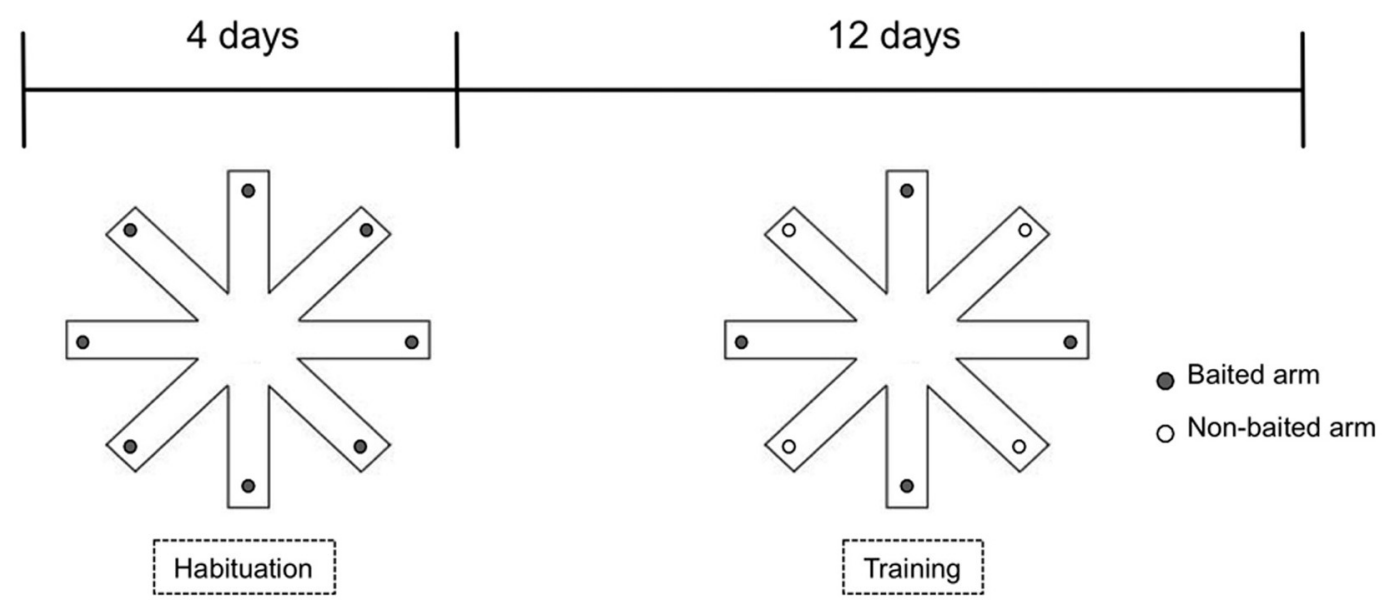

FIGURE 1 | Experimental setup of eight-arm radial maze test used for assessing reward-motivated learning and memory. 


\section{Number of Arm Entries}
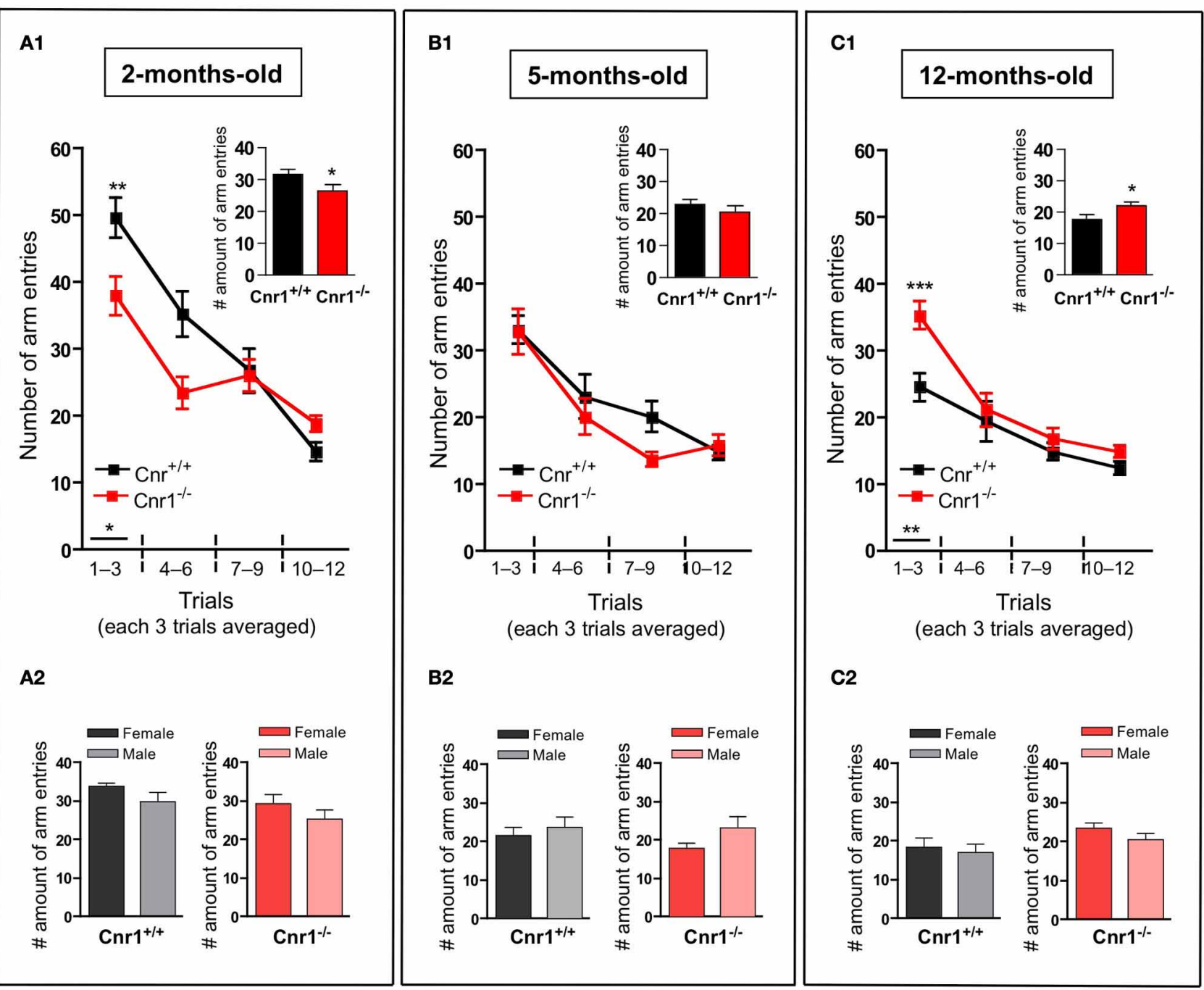

FIGURE 2 | Age-related changes in the number of arm entries in the eight-arm radial maze test between wild-type and $\mathrm{Cnr1}^{-/-}$mice. Each value represents the number of arm entries made until the mouse acquired all the rewards; mean \pm S.E.M. $(\mathbf{A} 1, \mathbf{B 1}, \mathbf{C 1})$ on each of 4 blocks of 3 trial days. Graph inserts show the average of all trial days separately by age group. (A2,B2,C2) Show the main effects of genotype for males and females mice separately by each age group, mean \pm S.E.M. for each sex and genotype averaged over the all trial days. The data were analyzed by Two-Way analyses of variance (ANOVA) followed by Bonferroni post-hoc test or One-Way analyses of variance (ANOVA) followed by Dunnett post-hoc test; ${ }^{*} p<0.05 ;{ }^{* *} p<0.01 ;{ }^{* * *} p<0.001$. ( $n=12$ mice/group; 6 females and 6 males). entries within a minute was significantly higher in 2-months-old mice compared to the other age-groups (Figure 5A1). A similar, but not significant tendency was observed in $\mathrm{Cnr1}^{-/-}$mice (Figure 5B1). However, there was no difference in the speed between the age groups when we evaluated each trial together (Figures 5A2,B2).

In the eight-arm radial maze test of appetitive conditioning, $\mathrm{Cnr1}^{-/-}$mice begin to show impairments at 12 -months-old compared to age-matched WT controls that is similar, albeit at a slightly older age, to results using an aversive conditioning paradigm (Albayram et al., 2011).

\section{DISCUSSION}

Our present study using the radial arm maze shows that the lifelong deletion of CB1 receptors has opposite effects on young and old animals, as also found in the Morris water maze test (Albayram et al., 2011). Thus, our result suggests that age-related effect of CB1 receptor activity is the same on reward and aversivedriven models of learning.

Cannabinoid signaling is involved in reward signaling and influences stress reactivity. Genetic deletion or pharmacological blockade of CB1 receptor decreases sensitivity to reward (Xi et al., 2008; Oleson et al., 2012) but exacerbates stress reactivity (Griebel 


\section{Working Memory Errors}

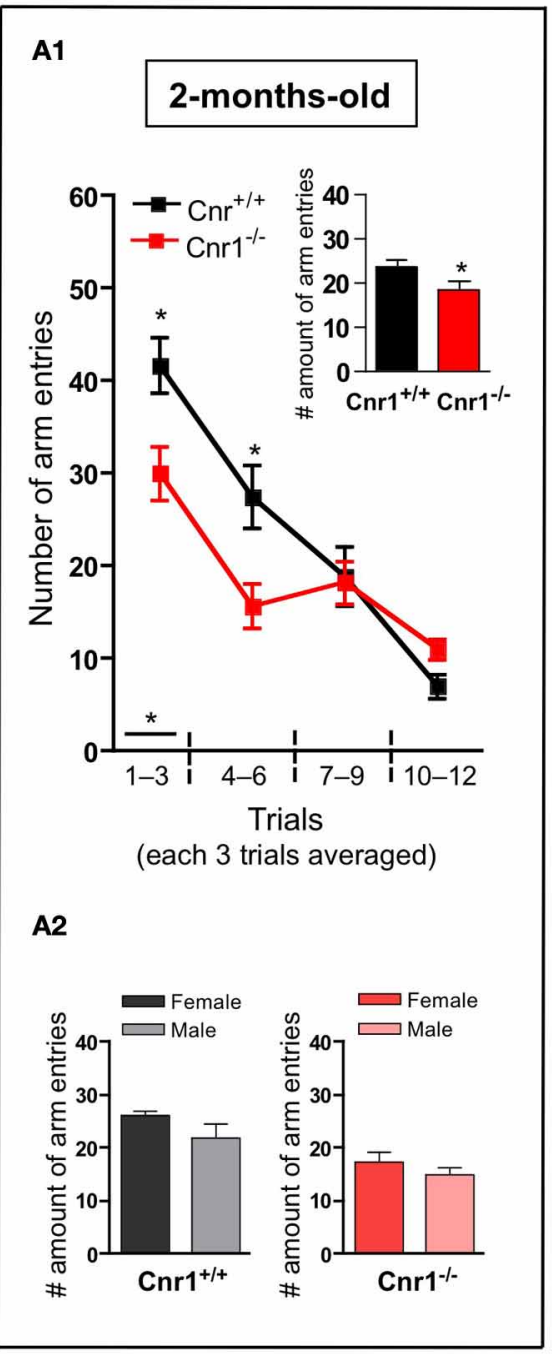

FIGURE 3 | Age-related changes in the working memory errors in the eight-arm radial maze test between wild-type and $\mathrm{Cnr1}^{-/-}$mice. Each value represents the working memory errors made until the mouse

acquired all the rewards; mean \pm S.E.M. $(\mathbf{A 1}, \mathbf{B 1}, \mathbf{C 1})$ on each of 4 blocks of 3 trial days. Graph inserts show the average of all trial days separately by age group. (A2,B2,C2) Show the main effects of genotype for males and

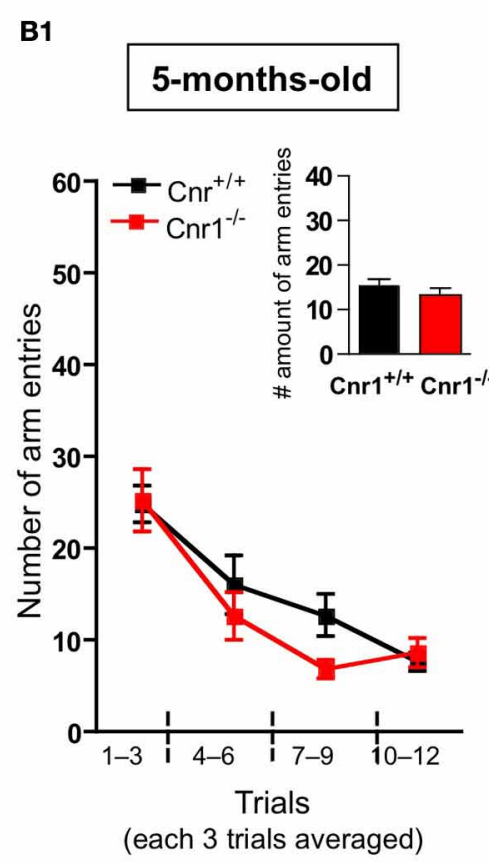

B2

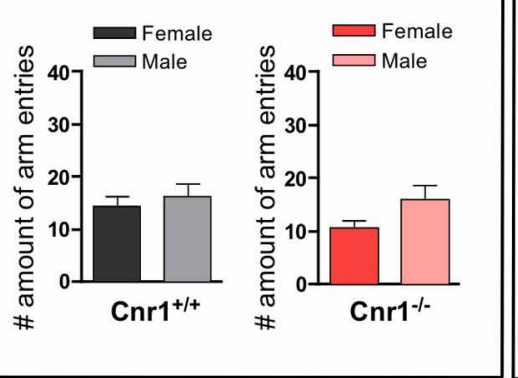

C1

\section{2-months-old}
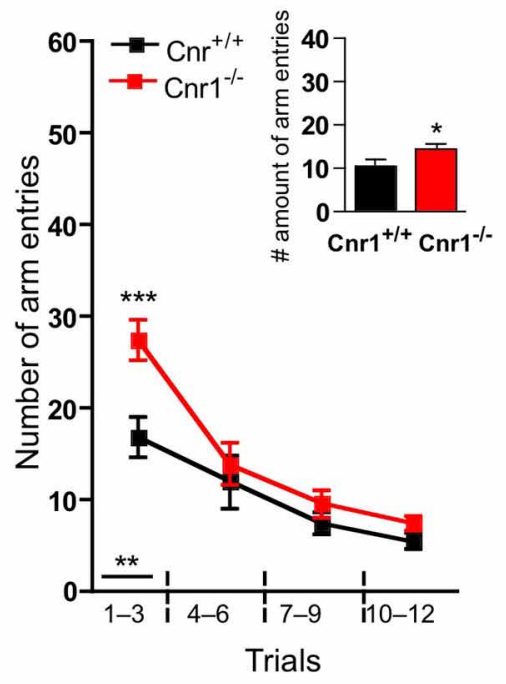

(each 3 trials averaged)

C2
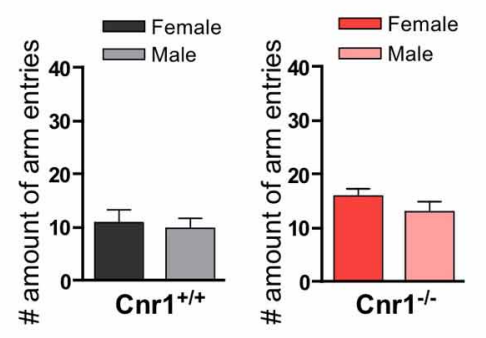

et al., 2005; Riebe and Wotjak, 2011; Gunduz-Cinar et al., 2012). These data together with findings showing that cannabinoid signaling differently affects memories with positive and negative emotional valence (Marsicano et al., 2002; Laviolette and Grace, 2006; Terzian et al., 2011) strongly suggests that the role and activity of the cannabinoid system differs in reward and fearrelated neuronal pathways and brain areas. In aging, however, our study now suggests that the effect of enhanced neuronal loss (Bilkei-Gorzo et al., 2005) and increased neuroinflammation in the hippocampus of $\mathrm{Cnr}^{-/-}$animals (Albayram et al., 2011) generally impairs hippocampal learning and memory affecting both reward and aversion-driven spatial learning. females mice separately by age group, mean \pm S.E.M. for each sex and genotype averaged over the all trial days. The data were analyzed by Two-Way analyses of variance (ANOVA) followed by Bonferroni post-hoc test or One-Way analyses of variance (ANOVA) followed by Dunnett post-hoc test; ${ }^{*} p<0.05$; ${ }^{* *} p<0.01$; ${ }^{* * *} p<0.001$. ( $n=12$ mice/group; 6 females and 6 males). 


\section{Reference Memory Errors}
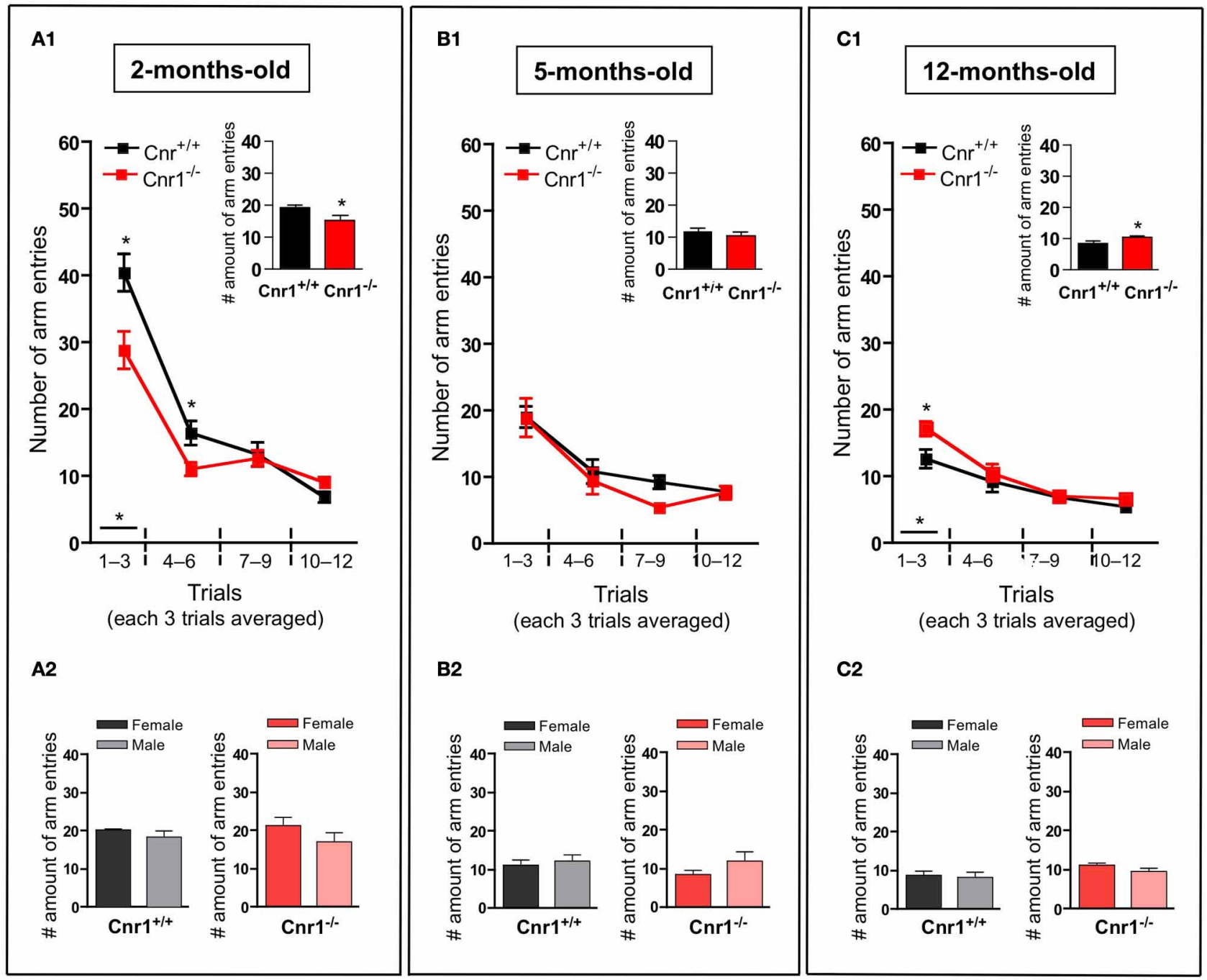

FIGURE 4 | Age-related changes in the reference memory errors in the eight-arm radial maze test between wild type and Cnr1-/- mice. Each value represents the reference memory errors made until the mouse acquired all the rewards; mean \pm S.E.M. (A1,B1,C1) on each of 4 blocks of 3 trial days. Graph inserts show the averaged of all trial days separately by age group. (A2,B2,C2) show the main effects of genotype for males and females mice separately by age group, mean \pm S.E.M. for each sex and genotype averaged over the all trial days The data were analyzed by Two-Way analyses of variance (ANOVA) followed by Bonferroni post-hoc test or One-Way analyses of variance (ANOVA) followed by Dunnett post-hoc test; ${ }^{*} p<0.05$ ( $n=12$ mice/group; 6 females and 6 males). arm maze test as pharmacological blockade of CB1 receptors. Although experimental evidence about the effect of CB1 receptor antagonist on old animals in the eight-arm maze test is lacking, it is unlikely that long-term pharmacological treatment can equate life-long deletion of the $\mathrm{CB} 1$ receptors and thus longterm antagonist treatment would be not feasible (Kunos and Tam, 2011).

An interesting aspect of our work is that males and females showed a similar performance although earlier studies using the Morris water maze paradigm suggested that the spatial learning abilities differs between the sexes (Clinton et al., 2007; HebdaBauer et al., 2007). A possible reason for this discrepancy is that the test situation is highly aversive in the Morris water maze test (Thorsell et al., 2000), whereas the eight-arm radial maze test condition is much less stressful, since it is based on the innate drive of the to explore the environment and seeking for food (Lehmann et al., 2010). Environmental stress influences memory formation differently in males and females (Andreano and Cahill, 2009; Oldehinkel and Bouma, 2011). Epidemiological studies in humans (Luine, 2002; Richardson and VanderKaay Tomasulo, 2011) and experimental studies in rodents (Sanders et al., 2011; ter Horst et al., 2011) together suggest that sexual dimorphisms in the hypothalamic-pituitary-adrenal axis response are responsible for these effects. Apparently, females are more sensitive to 
Number of Arm Entries / Time
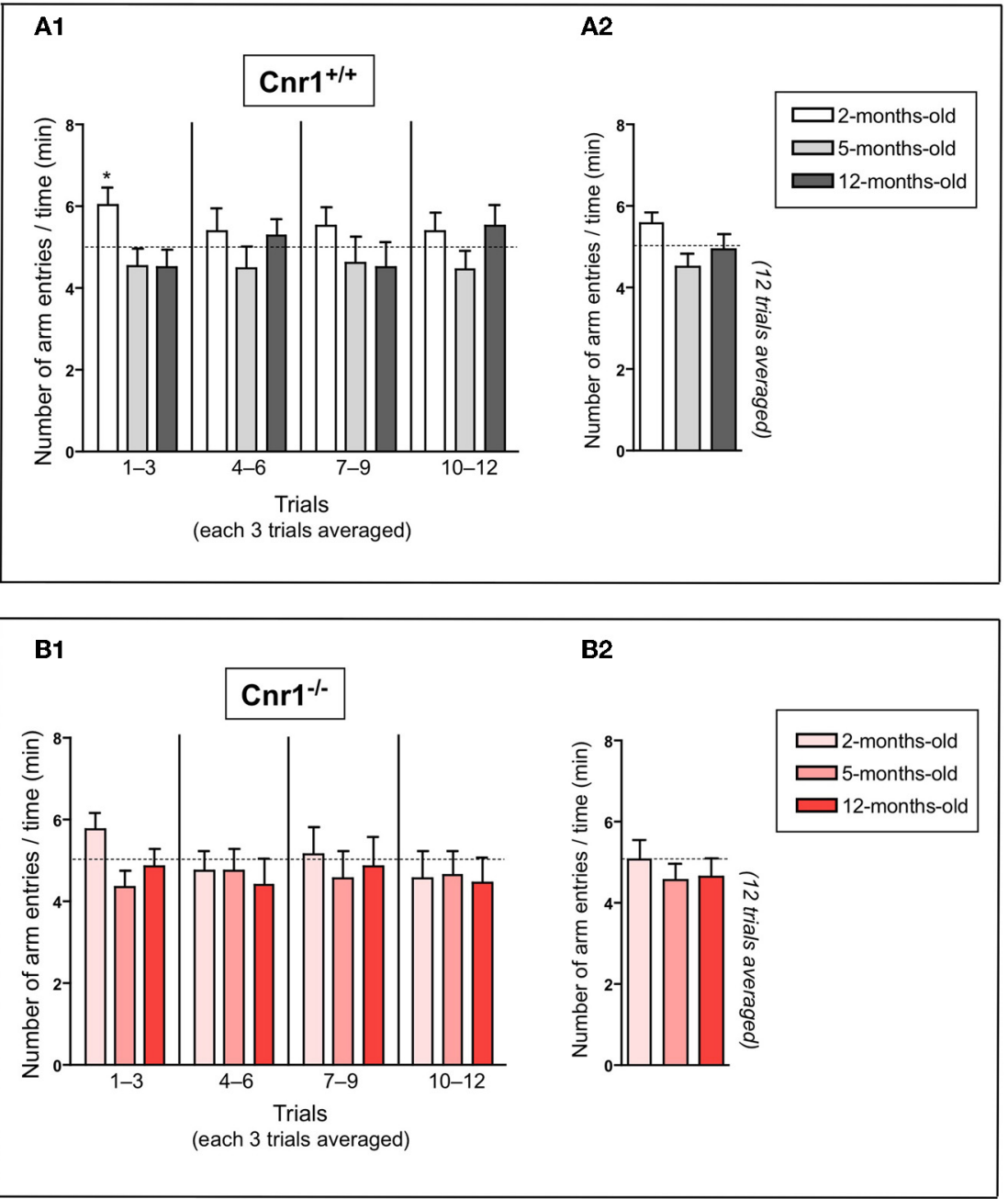

FIGURE 5 | The ratio between number of arm entries and time spent until the mouse acquired all the rewards in the eight-arm radial maze test. There is a significant age effect on day 1-3 (A1,B1), 2-months-old mice initially made more errors in a shorter period but quickly learned the task. The data were analyzed by One-Way analyses of variance (ANOVA) followed by Dunnett post-hoc test; ${ }^{*} p<0.05$ ( $n=12$ mice/group; 6 females and 6 males). No significant age effect for the 12 trials average of all trial days by each genotype (A2,B2) using One-Way ANOVA. the effect of stress due to fluctuations in gonadal hormone levels (Paris et al., 2011). Indeed, recent studies have revealed that gonadal hormones have a beneficial effect on memory formation in females under stressful conditions (Streeten et al., 1984). However, the stress response is not consistently different between the sexes in adolescents (Stoney et al., 1987; Gallucci et al., 1993; Greenspan et al., 1993), whereas this effect is present when testing adults (Peskind et al., 1995; Thorsell et al., 2000). Thus, we propose that the difference in the learning ability between the sexes in the Morris water maze test is based on their difference in stress sensitivity. This phenomenon was probably not present in the less aversive model of spatial learning - in the eight-arm maze paradigm - and therefore did not influence the performance of the animals.

Multiple lines of evidence prove that more emotional events are remembered better than non-emotional ones (Hamann, 2001;
LaBar and Cabeza, 2006). Although the input of emotions on memories is also present in the old, especially when emotional arousal is high (da Silva et al., 2007; Kensinger, 2008; RamirezLugo et al., 2009), its effect becomes less and less pronounced during ageing (Comblain et al., 2004; Bressler et al., 2010). Our results now suggest that the decreasing CB1 receptor signaling during ageing (Wang et al., 2003; Canas et al., 2009) does not contribute to this effect.

\section{ACKNOWLEDGMENTS}

This work was financed by the grant of the German Research Council (FOR926 SP2, SP3, SP6, CP2, and SFB645TBP7). We highly appreciate the help of Dr. Sophie Imbeault for reading and correcting the manuscript and the help of Dr. Anastasia Piyanova and Kerstin Michel helping by the design of eight-arm radial maze test. 


\section{REFERENCES}

Akirav, I., Sandi, C., and Richter-Levin, G. (2001). Differential activation of hippocampus and amygdala following spatial learning under stress. Eur. J. Neurosci. 14, 719-725.

Albayram, O., Alferink, J., Pitsch, J., Piyanova, A., Neitzert, K., Poppensieker, K., et al. (2011). Role of $\mathrm{CB} 1$ cannabinoid receptors on GABAergic neurons in brain aging. Proc. Natl. Acad. Sci. U.S.A. 108, 11256-11261.

Andreano, J. M., and Cahill, L. (2009). Sex influences on the neurobiology of learning and memory. Learn. Mem. 16, 248-266.

Bilkei-Gorzo, A., Racz, I., Valverde, O., Otto, M., Michel, K., Sastre, M., et al. (2005). Early age-related cognitive impairment in mice lacking cannabinoid CB1 receptors. Proc. Natl. Acad. Sci. U.S.A. 102, 15670-15675.

Bressler, A., Blizard, D., and Andrews, A. (2010). Low-stress route learning using the Lashley III maze in mice. J. Vis. Exp. 19, pii: 1786. doi: $10.3791 / 1786$

Canas, P. M., Duarte, J. M., Rodrigues, R. J., Kofalvi, A., and Cunha, R. A. (2009). Modification upon aging of the density of presynaptic modulation systems in the hippocampus. Neurobiol. Aging 30, 1877-1884.

Chhatwal, J. P., and Ressler, K. J. (2007). Modulation of fear and anxiety by the endogenous cannabinoid system. CNS Spectr. 12, 211-220.

Clinton, L. K., Billings, L. M., Green, K. N., Caccamo, A., Ngo, J., Oddo, S., et al. (2007). Age-dependent sexual dimorphism in cognition and stress response in the $3 \mathrm{xTg}-\mathrm{AD}$ mice. Neurobiol. Dis. 28, 76-82.

Comblain, C., D'Argembeau, A., Van der Linden, M., and Aldenhoff, L. (2004). The effect of ageing on the recollection of emotional and neutral pictures. Memory 12, 673-684.

da Silva, A. L., Piato, A. L., Ferreira, J. G., Martins, B. S., Nunes, D. S., and Elisabetsky, E. (2007). Promnesic effects of Ptychopetalum olacoides in aversive and non-aversive learning paradigms. J. Ethnopharmacol. 109, 449-457.

Dodart, J. C., Meziane, H., Mathis, C., Bales, K. R., Paul, S. M., and Ungerer, A. (1999). Behavioral disturbances in transgenic mice overexpressing the V717F beta-amyloid precursor protein. Behav. Neurosci. 113, 982-990.

Gallucci, W. T., Baum, A., Laue, L., Rabin, D. S., Chrousos, G. P., Gold, P. W., et al. (1993). Sex differences in sensitivity of the hypothalamicpituitary-adrenal axis. Health Psychol. 12, 420-425.

Greenspan, S. L., Rowe, J. W., Maitland, L. A., McAloon-Dyke, M., and Elahi, D. (1993). The pituitaryadrenal glucocorticoid response is altered by gender and disease. J. Gerontol. 48, M72-M77.

Griebel, G., Stemmelin, J., and Scatton, B. (2005). Effects of the cannabinoid CB1 receptor antagonist rimonabant in models of emotional reactivity in rodents. Biol. Psychiatry 57, 261-267.

Gunduz-Cinar, O., Macpherson, K. P., Cinar, R., Gamble-George, J., Sugden, K., Williams, B., et al. (2012). Convergent translational evidence of a role for anandamide in amygdala-mediated fear extinction, threat processing and stress-reactivity. Mol. Psychiatry. doi: 10.1038/mp.2012.72. [Epub ahead of print].

Hamann, S. (2001). Cognitive and neural mechanisms of emotional memory. Trends Cogn. Sci. 5, 394-400.

Hariri, A. R., Gorka, A., Hyde, L. W., Kimak, M., Halder, I., Ducci, F., et al. (2009). Divergent effects of genetic variation in endocannabinoid signaling on human threatand reward-related brain function. Biol. Psychiatry 66, 9-16.

Hebda-Bauer, E. K., Luo, J., Watson, S. J., and Akil, H. (2007). Female CREBalphadelta- deficient mice show earlier age-related cognitive deficits than males. Neuroscience 150, 260-272.

Heldt, S. A., Stanek, L., Chhatwal, J. P., and Ressler, K. J. (2007). Hippocampus-specific deletion of BDNF in adult mice impairs spatial memory and extinction of aversive memories. Mol. Psychiatry 12, 656-670.

Holter, S. M., Kallnik, M., Wurst, W., Marsicano, G., Lutz, B., and Wotjak, C. T. (2005). Cannabinoid CB1 receptor is dispensable for memory extinction in an appetitivelymotivated learning task. Eur. J. Pharmacol. 510, 69-74.

Kensinger, E. A. (2008). Age differences in memory for arousing and nonarousing emotional words. J. Gerontol. B Psychol. Sci. Soc. Sci. 63, P13-P18.

Kunos, G., and Tam, J. (2011). The case for peripheral $\mathrm{CB}(1)$ receptor blockade in the treatment of visceral obesity and its cardiometabolic complications. Br. J. Pharmacol. 163, 1423-1431.

LaBar, K. S., and Cabeza, R. (2006). Cognitive neuroscience of emotional memory. Nat. Rev. Neurosci. 7, 54-64.

Laviolette, S. R., and Grace, A. A (2006). Cannabinoids potentiate emotional learning plasticity in neurons of the medial prefrontal cortex through basolateral amygdala inputs. J. Neurosci. 26, 6458-6468.

Lehmann, M. L., Brachman, R. A. Listwak, S. J., and Herkenham, M. (2010). NF-kappaB activity affects learning in aversive tasks: possible actions via modulation of the stress axis. Brain Behav. Immun. 24 1008-1017.

Lichtman, A. H. (2000). SR 141716A enhances spatial memory as assessed in a radial-arm maze task in rats. Eur. J. Pharmacol. 404, 175-179.

Lichtman, A. H., and Martin, B. R (1996). Delta 9-tetrahydrocannabinol impairs spatial memory through a cannabinoid receptor mechanism. Psychopharmacology (Berl.) 126, 125-131.

Luine, V. (2002). Sex differences in chronic stress effects on memory in rats. Stress 5, 205-216.

Manwell, L. A., Satvat, E., Lang, S. T. Allen, C. P., Leri, F., and Parker, L. A. (2009). FAAH inhibitor, URB-597, promotes extinction and $\mathrm{CB}(1)$ antagonist, SR141716, inhibits extinction of conditioned aversion produced by naloxoneprecipitated morphine withdrawal, but not extinction of conditioned preference produced by morphine in rats. Pharmacol. Biochem. Behav. 94, 154-162.

Marsicano, G., Wotjak, C. T., Azad, S C., Bisogno, T., Rammes, G., Cascio, M. G., et al. (2002). The endogenous cannabinoid system controls extinction of aversive memories. Nature 418, 530-534

Morris, R. G., Garrud, P., Rawlins, J. N., and O'Keefe, J. (1982). Place navigation impaired in rats with hippocampal lesions. Nature 297, 681-683.

Oldehinkel, A. J., and Bouma, E. M. (2011). Sensitivity to the depressogenic effect of stress and HPA-axis reactivity in adolescence: a review of gender differences. Neurosci. Biobehav. Rev. 35, 1757-1770.

Oleson, E. B., Beckert, M. V., Morra J. T., Lansink, C. S., Cachope, R., Abdullah, R. A., et al. (2012). Endocannabinoids shape accumbal encoding of cue-motivated behavior via $\mathrm{CB} 1$ receptor activation in the ventral tegmentum. Neuron 73 360-373.

Paris, J. J., Walf, A. A., and Frye, C. A. (2011). II. Cognitive performance of middle-aged female rats is influenced by capacity to metabolize progesterone in the prefrontal cortex and hippocampus. Brain Res. 1379, 149-163.

Peskind, E. R., Raskind, M. A. Wingerson, D., Pascualy, M., Thal, L. J., Dobie, D. J., et al. (1995) Enhanced hypothalamic-pituitaryadrenocortical axis responses to physostigmine in normal aging. J. Gerontol. A Biol. Sci. Med. Sci. 50, M114-M120.

Ramirez-Lugo, L., Jensen, M. S., Soderman, A., and West, M. J. (2009). Deficits in aversive but not in safe taste memory in the APPswe/PS1dE9 mice. J. Alzheimers Dis. 18, 281-293.

Richardson, A. E., and VanderKaay Tomasulo, M. M. (2011). Influence of acute stress on spatial tasks in humans. Physiol. Behav. 103, 459-466.

Riebe, C. J., and Wotjak, C. T. (2011). Endocannabinoids and stress. Stress 14, 384-397.

Sanders, M. J., Stevens, S., and Boeh, H. (2011). Stress enhancement of fear learning in mice is dependent upon stressor type: effects of sex and ovarian hormones. Neurobiol. Learn. Mem. 94, 254-262.

Stoney, C. M., Davis, M. C., and Matthews, K. A. (1987). Sex differences in physiological responses to stress and in coronary heart disease: a causal link? Psychophysiology 24, 127-131.

Streeten, D. H., Anderson, G. H. Jr., Dalakos, T. G., Seeley, D., Mallov, J. S., Eusebio, R., et al. (1984) Normal and abnormal function of the hypothalamic-pituitaryadrenocortical system in man. Endocr. Rev. 5, 371-394.

ter Horst, J. P., de Kloet, E. R., Schachinger, H., and Oitzl, M. S. (2011). Relevance of stress and female sex hormones for emotion and cognition. Cell. Mol. Neurobiol. $32,725-735$.

Terzian, A. L., Drago, F., Wotjak, C. T., and Micale, V. (2011) The dopamine and cannabinoid interaction in the modulation of emotions and cognition: assessing the role of cannabinoid CB1 receptor in neurons expressing dopamine D1 receptors. Front. Behav. Neurosci. 5:49. doi: 10.3389/fnbeh.2011.00049

Thorsell, A., Michalkiewicz, M., Dumont, Y., Quirion, R. Caberlotto, L., Rimondini, R., et al. (2000). Behavioral insensitivity to restraint stress, absent fear suppression of behavior and impaired 
spatial learning in transgenic rats with hippocampal neuropeptide Y overexpression. Proc. Natl. Acad. Sci. U.S.A. 97, 12852-12857.

Varvel, S. A., Wise, L. E., Niyuhire, F., Cravatt, B. F., and Lichtman, A. H. (2007). Inhibition of fatty-acid amide hydrolase accelerates acquisition and extinction rates in a spatial memory task. Neuropsychopharmacology 32, 1032-1041.

Wang, L., Liu, J., Harvey-White, J., Zimmer, A., and Kunos, G. (2003). Endocannabinoid signaling via cannabinoid receptor 1 is involved in ethanol preference and its age-dependent decline in mice. Proc. Natl. Acad. Sci. U.S.A. 100, 1393-1398.

Ward, M. T., Stoelzel, C. R., and Markus, E. J. (1999). Hippocampal dysfunction during aging II: deficits on the radial-arm maze. Neurobiol. Aging 20, 373-380.

Ward, S. J., Rosenberg, M., Dykstra, L. A., and Walker, E. A. (2009). The CB1 antagonist rimonabant (SR141716) blocks cue-induced reinstatement of cocaine seeking and other context and extinction phenomena predictive of relapse. Drug Alcohol Depend. 105, 248-255.

Wise, L. E., Iredale, P. A., and Lichtman, A. H. (2008). The cannabinoid $\mathrm{CB}(1)$ receptor antagonist $\mathrm{CE}$ prolongs spatial memory duration in a rat delayed radial arm maze memory task. Eur. J. Pharmacol. 590, 246-249.

Wise, L. E., Thorpe, A. J., and Lichtman, A. H. (2009). Hippocampal $\mathrm{CB}(1)$ receptors mediate the memory impairing effects of Delta(9)-tetrahydrocannabinol.
Neuropsychopharmacology 2072-2080.

Xi, Z. X., Spiller, K., Pak, A. C., Gilbert, J., Dillon, C., Li, X., et al. (2008). Cannabinoid CB1 receptor antagonists attenuate cocaine's rewarding effects: experiments with self-administration and brain-stimulation reward in rats. Neuropsychopharmacology 33, 1735-1745.

Zimmer, A., Zimmer, A. M., Hohmann, A. G., Herkenham, M., and Bonner, T. I. (1999). Increased mortality, hypoactivity, and hypoalgesia in cannabinoid $\mathrm{CB} 1$ receptor knockout mice. Proc. Natl. Acad. Sci. U.S.A. 96, 5780-5785.

Conflict of Interest Statement: The authors declare that the research was conducted in the absence of any commercial or financial relationships
4, that could be construed as a potential conflict of interest.

Received: 23 August 2012; paper pending published: 20 September 2012; accepted: 19 November 2012; published online: 05 December 2012.

Citation: Albayram O, Bilkei-Gorzo A and Zimmer A (2012) Loss of CB1 receptors leads to differential age-related changes in reward-driven learning and memory. Front. Ag. Neurosci. 4:34. doi: 10.3389/fnagi.2012.00034

Copyright (c) 2012 Albayram, BilkeiGorzo and Zimmer. This is an openaccess article distributed under the terms of the Creative Commons Attribution License, which permits use, distribution and reproduction in other forums, provided the original authors and source are credited and subject to any copyright notices concerning any third-party graphics etc. 